\title{
A Cans Waste Classification System Based on RGB Images Using Different Distances of K-Means Clustering
}

\author{
Y Resti $^{1 *}$, F Nasution ${ }^{1}$, I Yani $^{2}$, AS Mohruni ${ }^{2}$, FA Almahdini $^{2}$, DA Zayanti ${ }^{1}$ \\ ${ }^{1}$ Jurusan Matematika Fakultas MIPA Universitas Sriwijaya, \\ Jl. Raya Palembang-Prabumulih Km.32 Inderalaya 30662, Ogan Ilir, Sumatera Selatan, Indonesia \\ ${ }^{2} J u r u s a n$ Teknik Mesin Fakultas Teknik Universitas Sriwijaya, \\ Jl. Raya Palembang-Prabumulih Km.32 Inderalaya 30662, Ogan Ilir, Sumatera Selatan, Indonesia \\ Email: yulia_resti@mipa.unsri.ac.id
}

Article Information:
Received:
6 March 2020
Received in revised form:
2 May 2020
Accepted:
5 May 2020
Volume 2 , Issue 1 , June 2020
pp. 53 - 57
C Universitas Lampung
http: //dx.doi.org/ $10.23960 /$ jesr.v2i1.35

\begin{abstract}
This study aims to build a classify the cans waste based on the pixel of captured Red, Green, and Blue (RGB) image by implement different metric 3 distances of $k$ means clustering; Manhattan, Euclidean, and Minkowski metric distance. The image capturing is designed using combinations of two the conveyor belt speeds of $0.181 \mathrm{~m} / \mathrm{sec}$ and $0.086 \mathrm{~m} / \mathrm{sec}$, two the lightings of halogen and incandescent lamps, and four lighting angles of 300,450,600, and 900. The classification results note that the implementation of Manhattan distance on the k-means clustering method for classifying the cans waste into three can types has the highest level of accuracy in the majority of data. The highest accuracy level of classification is obtained from data of captured image on the conveyor belt speeds of $0.181 \mathrm{~m} / \mathrm{sec}$, the lightings of halogen lamp, and the lighting angles of 450 by implementing the Euclidean distance, while the lowest accuracy level of classification is obtained from data of captured image on the lighting angles of 300 with the same speeds and the lamp by implementing the Manhattan distance. The highest average accuracy is obtained by implementing the Euclidean distance, that derived from the average accuracy at lighting angle of 450 .
\end{abstract}

Keywords:

\section{INTRODUCTION}

$\mathrm{I}$ $\mathrm{N}$ a technology that applies automation systems such as sorting systems in the recycling industry, a classification system is needed in the identification process. A classification system for cans waste types based on Red, Green, and Blue colors (RGB) image pixel has been developed by Resti [1], Resti et al [2] and Yani et al [3-4]. They built the system based on the capture of RGB images from cans placed on a static conveyor belt and room lighting. The classification methods they use are naive Bayes, k-NN and multinomial regression.

The k-mean clustering method is one of the essential methods for grouping (classification) objects into desired k-groups. Some studies that have recently applied this method are Perez-Ortega et al [5], Di \& Gou [6], Franti \& Sieranoja [7], Kumar \& Kaur [8], and Bansal et al [9]. This K-means clustering method determine the distance between each data point and the center of the cluster (centroid) that corresponds using a metric size. The metric size that is often used (as default) to calculate the distance is Euclidean $[6,8,9]$. Besides Euclidean, other metric distances can also be used such as Manhattan, Chebychev, and Minkowski distance [10 - 14]

In this study, a can classification system was built based on RGB image capture of cans placed on a conveyor belt with the certain speeds, lighting sources, and lighting angles. The classification method used is k-means clustering with 3 different metric distances; Euclidean, Manhattan, and Minkowski.

\section{Materials AND Methods}

This cans waste classification system based on RGB images is designed using combinations of two the conveyor belt speeds of $0.181 \mathrm{~m} / \mathrm{sec}$ and $0.086 \mathrm{~m} / \mathrm{sec}$, two the lightings of halogen and incandescent lamps which are mounted with a certain angle. Four the lighting angles in this capturing system are $30^{\circ}, 45^{\circ}$, $60^{\circ}$, and $90^{\circ}$. Suppose $X_{1 i}, X_{2 i}, \cdots X_{9 i}$ are input variables that represent the pixel of red, green, and blue 
colors successively of the $i$-th cans image captured at the top, down, and side poses respectively. The nine input variables each have a centroid for each type of $j$ can that is denoted by $X_{1 j}, X_{2 j}, \cdots, X_{9 j}$. The method starts by selecting $\mathrm{k}$ random data points (cans images in pixel) as the initial centroids. The $i$-th can image in pixel will be grouped into the $j$-th can type if it has the smallest $D(i, j)$, where the metric distance from the $i$ th can waste to the centroid of the $j$-can waste type defined as,

$D(i, j)=\left|X_{1 i}-X_{1 j}\right|+\left|X_{2 i}-X_{2 j}\right|+\cdots+\left|X_{k i}-X_{k j}\right|$

or

$D(i, j)=\sqrt{\left(X_{1 i}-X_{1 j}\right)^{2}+\left(X_{2 i}-X_{2 j}\right)^{2}+\cdots+\left(X_{k i}-X_{k j}\right)^{2}}$

or

$D(i, j)=\sqrt[p]{\left|X_{1 i}-X_{1 j}\right|^{p}+\left|X_{2 i}-X_{2 j}\right|^{p}+\cdots+\left|X_{k i}-X_{k j}\right|^{p}}$

Equations (1) - (3) are referred to respectively as the Manhattan, Euclid, and Minkowski distances, where the Minkowski distance is a generalization of both the Euclidean distance and the Manhattan distance. The centroid is then updated by recalculating it as the average of all data points specified in each cluster. These calculations are repeated until no further improvement is obtained (convergence). For each metric distance in this study, $k$ initial centroid was randomly selected from all cans waste data, where $k$ is the number of can types.

\section{RESULTS AND DISCUSSIONS}

The process of classification the cans waste based on the RGB images into 3 types: tin plate, aluminum, and aerosol cans using three metric distances as formulated in (1) - (3) is done with the help of R programming language and R Studio software. Table 1 - Table 7 only shows results for conveyor belt speeds of $0.086 \mathrm{~m} / \mathrm{s}$ and lighting angle of $45^{\circ}$. The initial centroid randomly selected for each variable and can type is given in Table 1.

Table 1. The Initial Centroids are selected randomly for each variable and can type

\begin{tabular}{cccccccccc}
\hline cans type & \multicolumn{8}{c}{ Input variable } \\
\cline { 2 - 9 }$(j-$ th $)$ & $X_{1 i}$ & $X_{2 i}$ & $X_{3 i}$ & $X_{4 i}$ & $X_{5 i}$ & $X_{6 i}$ & $X_{7 i}$ & $X_{8 i}$ & $X_{9 i}$ \\
\hline 1 & 161.97 & 161.39 & 159.77 & 164.80 & 164.30 & 161.58 & 162.90 & 162.06 & 159.89 \\
2 & 156.89 & 156.62 & 156.48 & 161.15 & 160.77 & 160.96 & 158.77 & 156.57 & 157.64 \\
3 & 155.31 & 155.83 & 155.48 & 159.36 & 155.83 & 160.39 & 159.36 & 159.48 & 160.14 \\
\hline
\end{tabular}

The majority of initial centroids in the $1^{\text {st }}$ can type are larger than centroids in the other can type. In both the $1^{\text {st }}$ and $2^{\text {nd }}$ can type, the input variable that has the largest initial centroid is $X_{4 i}$ while the input variable that has the smallest initial centroid is $X_{3 i}$. Unlike the two can types, in the $3^{\text {rd }}$ can type, the input variable that has the largest initial centroid is $X_{6 i}$, while the input variable that has the smallest initial centroid is $X_{1 i}$.

Table 2. The New Centroids base on Manhattan distance

\begin{tabular}{cccccccccc}
\hline cans type & \multicolumn{8}{c}{ Input variable } \\
\cline { 2 - 10 }$(j$-th $)$ & $X_{1 i}$ & $X_{2 i}$ & $X_{3 i}$ & $X_{4 i}$ & $X_{5 i}$ & $X_{6 i}$ & $X_{7 i}$ & $X_{8 i}$ & $X_{9 i}$ \\
\hline 1 & 165.32 & 165.22 & 167.28 & 166.02 & 165.98 & 167.54 & 164.30 & 164.01 & 165.46 \\
2 & 158.97 & 158.92 & 159.38 & 160.27 & 160.09 & 160.45 & 157.18 & 156.77 & 156.94 \\
3 & 154.36 & 153.21 & 152.63 & 154.43 & 153.94 & 153.21 & 151.64 & 151.08 & 149.94 \\
\hline
\end{tabular}

Like the initial centroid, for the Manhattan distance, both the $1^{\text {st }}$ and $2^{\text {nd }}$ can types have the largest new centroid in the same variable but not the variable $X_{4 i}$ but the variable $X_{6 i}$, as well as the smallest centroid but not the variable $X_{3 i}$ but the variable $X_{8 i}$. In the $3^{\text {rd }}$ can
The data in Table 1 is used to calculate the distance of the metric in (1) - (3) and then results of the initial classification are obtained. Thus, the new centroid for each variable and cans type is calculated from the results of this initial grouping. This new centroid is the average of all cans. The centroid base on (1) - (3) and is shown in Table 2 - Table 4. type, the input variable that has the largest new centroid is $X_{4 i}$ while the smallest new centroid is $X_{8 i}$. The majority of new centroids base on Manhattan distance in the $1^{\text {st }}$ can type are larger than new centroids in the other can type. 
Table 3. The New Centroids base on Euclidean distance

\begin{tabular}{cccccccccc}
\hline cans type & \multicolumn{8}{c}{ Input variable } \\
\cline { 2 - 9 }$(j-$ th $)$ & $X_{1 i}$ & $X_{2 i}$ & $X_{3 i}$ & $X_{4 i}$ & $X_{5 i}$ & $X_{6 i}$ & $X_{7 i}$ & $X_{8 i}$ & $X_{9 i}$ \\
\hline 1 & 165.42 & 165.76 & 167.49 & 165.02 & 165.09 & 166.04 & 162.66 & 162.34 & 163.25 \\
2 & 158.10 & 158.14 & 158.22 & 159.27 & 159.23 & 159.54 & 156.29 & 155.94 & 156.03 \\
3 & 152.72 & 150.51 & 150.42 & 154.44 & 153.34 & 152.78 & 151.80 & 151.01 & 149.97 \\
\hline
\end{tabular}

For Euclidean distance, all of the new centroid in the $1^{\text {st }}$ can type as shown in Table 3 are the largest, while all of the new centroid in the $3^{\text {rd }}$ can type as shown in Table 3 are the smallest. In each of can type, the input variables that have the largest new centroid successively are $X_{3 i}, X_{6 i}, X_{4 i}$ while the input variables that have the smallest new centroid are $X_{8 i}, X_{8 i}, X_{3 i}$.

Table 4. The New Centroids base on Minkowski distance

\begin{tabular}{cccccccccc}
\hline cans type & \multicolumn{8}{c}{ Input variable } \\
\cline { 2 - 9 } (j-th) & $X_{1 i}$ & $X_{2 i}$ & $X_{3 i}$ & $X_{4 i}$ & $X_{5 i}$ & $X_{6 i}$ & $X_{7 i}$ & $X_{8 i}$ & $X_{9 i}$ \\
\hline 1 & 166.34 & 167.17 & 169.38 & 164.79 & 165.08 & 166.42 & 162.16 & 162.01 & 163.23 \\
2 & 158.26 & 158.12 & 158.14 & 159.83 & 159.71 & 159.92 & 157.00 & 156.58 & 156.60 \\
3 & 152.87 & 150.70 & 150.54 & 154.51 & 153.46 & 152.85 & 151.88 & 151.14 & 150.07 \\
\hline
\end{tabular}

As with the new centroids based on the Euclidean distance metric, in Table 4 it can be seen that all of the new centroid in the $1^{\text {st }}$ can type are the largest, while all of the new centroid in the $3^{\text {rd }}$ can type are the smallest. The input variables that have the largest new centroid in each of can type based on Minkowski distance are same with Euclidean distance successively are $X_{3 i}, X_{6 i}, X_{4 i}$. The smallest new centroid of both the $1^{\text {st }}$ and $2^{\text {nd }}$ can types is $X_{8 i}$, while of the $3^{\text {rd }}$ can type is $X_{8 i}$.

The new centroids in Table 2 - Table 4 are each used to calculate metric distances in (1) - (3) to reclassification cans by the type. The classification process based on each of the distance is carried out repeatedly until the members of each type of can do not move to other types of cans.

The results of this final classification for each metric distance are given in Table 5 - Table 7, while the level of accuracy of classification for each metric distance is given in Table 8.

Table 5. the final classification result using Manhattan distance

\begin{tabular}{ccccc}
\hline \multirow{2}{*}{$\begin{array}{c}\text { Manhattan } \\
\text { distance }\end{array}$} & \multicolumn{3}{c}{$\begin{array}{c}\text { Grouping result into the } \\
\text { can type }\end{array}$} \\
\cline { 2 - 5 } & 1 & 1 & 2 & 3 \\
\hline \multirow{3}{*}{ the can type } & 2 & 15 & 40 & 11 \\
\cline { 2 - 5 } & 3 & 11 & 43 & 15 \\
\hline
\end{tabular}

In Table 5, it can be seen that the classification results using Manhattan distance indicate that only in the $2^{\text {nd }}$ can type, the number of cans that enter the can type should be (the $2^{\text {nd }}$ cans type of can) is more than the other can types. In the $1^{\text {st }}$ cans type, the majority of cans from the $1^{\text {st }}$ cans type enter the $2^{\text {nd }}$ cans type, while in the $3^{\text {rd }}$ cans type, the number of cans that enter the $3^{\text {rd }}$ can type is the same as the number of cans that enter the $2^{\text {nd }}$ can type.

Table 6. the final classification result using Euclidean distance

\begin{tabular}{ccccc}
\hline \multirow{2}{*}{$\begin{array}{c}\text { Euclidean } \\
\text { distance }\end{array}$} & \multicolumn{3}{c}{$\begin{array}{c}\text { Grouping result into the } \\
\text { can type }\end{array}$} \\
\cline { 2 - 5 } & 1 & 1 & 2 & 3 \\
\hline \multirow{3}{*}{ the can type } & 2 & 34 & 35 & 5 \\
\cline { 2 - 5 } & 3 & 12 & 48 & 12 \\
\cline { 2 - 5 } & 3 & & & 36 \\
\hline
\end{tabular}

The classification results using Euclidean distance as presented in Table 6 also show that only in the $2^{\text {nd }}$ can type, the number of cans that enter the $2^{\text {nd }}$ cans type of can is more than the other can types. In the $1^{\text {st }}$ cans type, the number of cans that enter the $1^{\text {st }}$ can type is almost the same as the number of cans that enter the $2^{\text {nd }}$ can type, while in the $3^{\text {rd }}$ cans type, the majority of cans from the $3^{\text {rd }}$ cans type entered the $2^{\text {nd }}$ cans type.

Table 7. the final classification result using Minkowski distance

\begin{tabular}{ccccc}
\hline \multirow{2}{*}{$\begin{array}{c}\text { Minkowski } \\
\text { distance }\end{array}$} & \multicolumn{3}{c}{$\begin{array}{c}\text { Grouping result into the } \\
\text { can type }\end{array}$} \\
\cline { 2 - 5 } & & 1 & 2 & 3 \\
\hline \multirow{3}{*}{ the can type } & 1 & 31 & 37 & 6 \\
\cline { 2 - 5 } & 2 & 15 & 55 & 13 \\
\cline { 2 - 5 } & 3 & 13 & 44 & 36 \\
\hline
\end{tabular}


The final classification using Minkowski distance in Table 7 shows that in the $1^{\text {st }}$ can type, the number of cans from the $1^{\text {st }}$ can type that enter the $2^{\text {nd }}$ can type is more than the $1^{\text {st }}$ cans type, as well in the $3^{\text {rd }}$ can type, the number of cans from the $3^{\text {rd }}$ can type that enter the $2^{\text {nd }}$ can type is more than the $3^{\text {rd }}$ can type. The accuracy level of classification using three different distances for combination the conveyor belt speeds and the lighting angles are given in Table 8 - Table 11 .

Table 8. Accuracy level of classification using three different distances for angles of $30^{\circ}$

\begin{tabular}{clcccc}
\hline \multirow{2}{*}{ No. } & \multirow{2}{*}{ Metric Distances } & \multicolumn{4}{c}{ Classification accuracy level (\%) } \\
\cline { 3 - 6 } & & \multicolumn{2}{c}{ Speed of $0.181 \mathrm{~m} / \mathrm{s}$} & \multicolumn{2}{c}{ Speed of $0.086 \mathrm{~m} / \mathrm{s}$} \\
\hline & & Halogen & Incandescent & Halogen & Incandescent \\
\hline 1 & Manhattan & 20.8 & 27.2 & 36.0 & 39.2 \\
2 & Euclidean & 24.4 & 40.0 & 42.8 & 42.0 \\
3 & Minkowski & 25.6 & 40.0 & 38.0 & 38.4 \\
\hline
\end{tabular}

Table 8 shows that the highest accuracy level of cans classification for speed of $0.181 \mathrm{~m} / \mathrm{s}$ and halogen lamp is using Minkowski distance, while the both Euclidean and Minkowski distance has the accuracy level for incandescent lamp. For speed of $0.086 \mathrm{~m} / \mathrm{s}$, either halogen or incandescent lamp is using Euclidean distance.

Table 9. Accuracy level of classification using three different distances for angles of $45^{\circ}$

\begin{tabular}{clcccc}
\hline \multirow{2}{*}{ No. } & \multirow{2}{*}{ Metric Distances } & \multicolumn{4}{c}{ Classification accuracy level (\%) } \\
\cline { 3 - 6 } & & \multicolumn{2}{c}{ Speed $0.181 \mathrm{~m} / \mathrm{s}$} & \multicolumn{2}{c}{ Speed $0.086 \mathrm{~m} / \mathrm{s}$} \\
\hline & & Halogen & Incandescent & Halogen & Incandescent \\
\hline 1 & Manhattan & 35.8 & 30.4 & 46.4 & 29.6 \\
2 & Euclidean & 49.6 & 34.0 & 42.8 & 28.0 \\
3 & Minkowski & 40.8 & 35.6 & 42.8 & 27.6 \\
\hline
\end{tabular}

The results in Table 9 notes that for speed of 0.086 $\mathrm{m} / \mathrm{s}$, either halogen or incandescent lamp, the highest accuracy level of cans classification is using Manhattan distance, while for speed of $0.181 \mathrm{~m} / \mathrm{s}$ the highest accuracy is Euclidean distance for halogen lamp, and Minkowski distance for incandescent lamp.

Table 10. Accuracy level of classification using three different distances for angles of $60^{\circ}$

\begin{tabular}{clcccc}
\hline \multirow{2}{*}{ No. } & \multirow{2}{*}{ Metric Distances } & \multicolumn{3}{c}{ Classification accuracy level (\%) } \\
\cline { 3 - 6 } & & \multicolumn{2}{c}{ Speed $0.181 \mathrm{~m} / \mathrm{s}$} & \multicolumn{2}{c}{ Speed $0.086 \mathrm{~m} / \mathrm{s}$} \\
\hline & & Halogen & Incandescent & Halogen & Incandescent \\
\hline 1 & Manhattan & 37.6 & 28.8 & 29.6 & 29.2 \\
2 & Euclidean & 34.0 & 24.4 & 28.0 & 28.0 \\
3 & Minkowski & 35.6 & 32.4 & 29.2 & 28.0 \\
\hline
\end{tabular}

Table 10 present that the highest accuracy level of cans classification for speed of $0.181 \mathrm{~m} / \mathrm{s}$ is using Manhattan distance (halogen), and Minkowski distance (incandescent), while for speed of $0.086 \mathrm{~m} / \mathrm{s}$, either halogen or incandescent lamp is using Manhattan distance.

Table 11. Accuracy level of classification using three different distances for angles of $90^{\circ}$

\begin{tabular}{clcccc}
\hline \multirow{2}{*}{ No. } & \multirow{2}{*}{ Metric Distances } & \multicolumn{3}{c}{ Classification accuracy level (\%) } \\
\cline { 3 - 6 } & & \multicolumn{2}{c}{ Speed $0.181 \mathrm{~m} / \mathrm{s}$} & \multicolumn{2}{c}{ Speed $0.086 \mathrm{~m} / \mathrm{s}$} \\
\hline & & Halogen & Incandescent & Halogen & Incandescent \\
\hline 1 & Manhattan & 36.0 & 37.6 & 28.4 & 28.4 \\
2 & Euclidean & 39.6 & 37.2 & 40.0 & 22.0 \\
3 & Minkowski & 38.0 & 26.0 & 21.6 & 21.6 \\
\hline
\end{tabular}


Table 11 shows that the accuracy level of cans classification using Euclidean distance has the highest accuracy for halogen lamp, and using Manhattan distance has the highest accuracy for incandescent lamp.

\section{Conclusions}

This study developed a cans waste classification system based on RGB images capturing at two types of conveyor belt speed and four lighting angles. Implementation of three different metric distances on the k-means clustering method to classify the cans waste into three cans type indicates that the accuracy level of k-means clustering for three distance are not significantly different. The level of accuracy obtained is not satisfactory. The highest accuracy level of classification is obtained from data of captured image on the conveyor belt speeds of $0.181 \mathrm{~m} / \mathrm{sec}$, the lightings of halogen lamp, and the lighting angles of $45^{\circ}$ by implementing the Euclidean distance at $49.6 \%$, while the lowest accuracy level of classification is obtained from data of captured image on the lighting angles of $30^{\circ}$ with the same conveyor belt speeds and the lamp at $20.8 \%$.

\section{REFERENCES}

[1] Y. Resti, "Dependence in Classification of Aluminium Waste," Journal of Physics, vol. 622, 2015.

[2] Y. Resti, I. Yani, A. S. Mohruni, F. Burlian and A. Amran, "A probability approach in cans identification, MATEC Web of Conferences," in MATEC Web of Conferences, 2017.

[3] I. H. M. A. B. H. S. E. a. B. N. E. A. Yani, "Detecting Object Using Combination of Sharpening and Edge Detection Method," European Journal of Scientific Research, vol. 32, no. 1, p. 121-127, 2009.

[4] I. Yani, M. A. Hannan, H. Basri, E. Scavino and N. E. A. Basri, "An Automatic Sorting System for Recycling Beverage Cans using the Eigenface Algorithm," in The Third International Conference on
Soft Computing Technology in Civil, Structural and Environmental Engineering, 2013.

[5] J. A.-O. N. R. D. Pe'rez-Ortega, "Balancing effort and benefit of K-means clustering algorithm in Big Data realms," plos one, 2018.

[6] X. G. J Di, "Bisecting K-means Algorithm Based on K-valued Selfdetermining and Clustering Center Optimization," Journal of Computers, vol. 3, no. 16, p. 588-595, 2018.

[7] P. Franti and S. Sieranoja, "K-means properties on six clustering benchmark datasets," Apllied Intelligence, 2018.

[8] S. Kumar and S. Kaur, "Modified K-means Clustering Algorithm for Disease Prediction," International Journal of Engineering and Technquesm, vol. 3, no. 3, pp. 195-201, 2017.

[9] A. Bansal and S. G. M Sharma, "Improved K-mean Clustering Algorithm for Prediction Analysis using Classification Technique in Data Mining," International Journal of Computer Applications, vol. 157, no. 6, pp. 35-40, 2017.

[10] A. Singh, A. Yadav and A. Rana, "K-means with Three different Distance Metrics," International Journal of Computer Applications, vol. 67, no. 10, pp. 13-17, 2013.

[11] V. Gomath and V. Karthikeyan, "Performance Analysis of Distance Measures for Computer tomography Image Segmentation," Int.J.Computer Technology \& Applications, vol. 5, no. 2, pp. 400-405, 2014.

[12] T. Kirdat and V. V. Patil, "Application of Chebyshev Distance and Minkowski Distance to CBIR Using Color Histogram," International Journal of Innovative Research In Technology, vol. 2, no. 9, p. 2016, 28-31.

[13]C. Yuan and H. Yang, "Research on K-Value Selection Method of K-Means Clustering Algortihm," Multidiciplinary Scientific Journal, vol. 2, no. 16, pp. 226-235, 2019.

[14] M. Z. Rodriguez, C. H. Comin, D. Casanova, O. M. Bruno, D. R. Amancio, L. F. Costa and Rodrigues, "Clustering algorithms: A comparative approach," PLoS ONE, vol. 14, no. 1, 2019. 